\title{
Kendiliğinden organize olan tek tabaka molekülleri kullanarak organik sşık yayan diyotların veriminin iyileştirilmesi
}

\author{
Increasing efficiency of organic light emitting diode by using self assembled monolayers
}

\author{
Eyyup YALÇIN ${ }^{1, a}$, Burak GÜLTEKİN ${ }^{2, b}$, Hakan BíLGíLi ${ }^{3, c}$, Mustafa CAN ${ }^{* 4, d}$

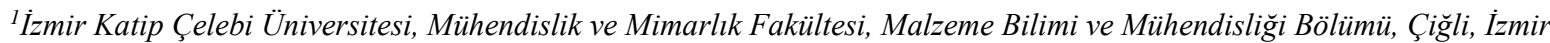 \\ ${ }^{2}$ Ege Üniversitesi, Güneș Enerjisi Enstitüsü, Bornova, İzmir \\ ${ }^{3}$ İzmir Katip Çelebi Üniversitesi, Merkezi Araştırma Laboratuvarları Uygulama ve Araştırma Merkezi, Çiğli, İzmir \\ ${ }^{4} \dot{I} z m i r$ Katip Çelebi Üniversitesi, Mühendislik Bilimleri Bölümü, Çiğli, İzmir
}

• Geliş tarihi / Received: 07.01.2021 • Düzeltilerek geliş tarihi / Received in revised form: 14.08.2021 • Kabul tarihi / Accepted: 04.09.2021

Öz

Ara yüzey iyileştirmeleri optoelektronik cihazların performansı üzerine önemli bir role sahiptir. Kendiliğinden organize olan tek tabaka molekülleri indiyum kalay oksit (ITO) ile organik katman arasında kullanılarak organik ışık yayan diyotlardan (OLEDs) daha yüksek performans elde edilmesi sağlanır. Bu çalı̧̧mada ITO’yu modifiye etmek için 4metoksifenil boronik asit ile 3,5-dimetoksifenil boronik asit molekülleri bir ara yüzey katmanı olarak kullanılmışıır. Kendiliğinden organize olan moleküllerinin cihaz performansı üzerine etkisi elektriksel ve optiksel olarak analiz edilmiştir. Buna ek olarak, modifiye edilmiş ITO’nun yüzey morfolojisi atomik kuvvet mikroskopu (AFM), yüzey ıslanabilirliği ise temas açısı yöntemi ile ölçülmüştür. Elde edilen sonuçlara göre, ITO yüzeyi kendiliğinden organize olan moleküller ile modifiye edilen cihazların modifiye edilmemiş cihazlara göre daha iyi performans sergilediği görülmüştür.

Anahtar kelimeler: Enerji verimliliği, Kendiliğinden organize tek tabaka moleküller, OLED

\begin{abstract}
Interface engineering has an important role on performance of optoelectronic devices. Self-assembled monolayers (SAMs) have been used between indium tin oxide (ITO) and organic layer to obtain high performance from organic lightemitting diodes (OLEDs). Herein, 4-Methoxyphenyl Boronic Acid and 3,5-Dimethoxyphenyl Boronic Acid have been used to ITO as an interface layer. The effect of SAMs on device performance was analyzed electrically and optically. Additionally, surfacre topography of modified ITO was characterized by atomic force microscope and surface wetability was analyzed by contact angle. According to results that has obtain, modified devices show better performance than unmodified devices.
\end{abstract}

Keywords: Energy efficiency, Self-assembled monolayers, OLED

\footnotetext{
${ }^{*}$ Mustafa CAN; mustafacan80@yahoo.com; Tel: (0532) 691 6926; orcid.org/0000-0002-1749-8293

${ }^{a}$ orcid.org/0000-0002-7468-2169 $\quad{ }^{b}$ orcid.org/0000-0002-8804-7844 $\quad{ }^{c}$ orcid.org/0000-0001-5646-6641
} 


\section{Giriş}

Organik 1şı yayan diyotlar (OLEDs) düşük çalışma voltajı ve yüksek dış kuantum verimine sahip olduğu 1987 yılında Tang ve VanSlyke tarafından rapor edildilmiştir. Aynı zamanda OLED'ler düşük güç tüketimi, düşük maliyeti, kendiliğinden 1şık verme özelliği, hızlı tepki süresi, geniş görüş açısı, yüksek verimlilik ve esneklik (Forrest, 2004; Kido vd., 1995; Eyyup Yalcin vd., 2017; Zheng vd., 2018) gibi özelliklerinden dolay1 bu alandaki çalışmalar son 30 y1llık süreçte oldukça hız kazanmıştır. $\mathrm{Bu}$ süre zarfinda OLED'lerin gerek verimliliğini artırmak gerek ise daha kararlı bir yapıya kavuşturmak için birçok yöntem denenmiştir. OLED'ler den daha iyi verim elde edilebilmesi için ilgili metal elektrotlardan (anot ve katot) organik yariiletken malzemeler içerisine etkili ve dengeli bir yük (elektron ve boşluk) geçişi sağlanmalıdır. Metal elektrotlar ile organik yarıiletkenlerin fark1 enerji seviyelerinde olmalarından dolayı yük geçiş bariyeri ile metal/organik arasında oluşan temas direnci, düşük yük geçişi ve düşük cihaz verimine neden olmaktadır. Bundan dolayı, metal elektrotlar ile organik yariiletkenler arasındaki ara yüzey, yük geçişi ve yük dengesi üzerine dolayısı ile cihaz verimi üzerinde önemli bir etkiye sahiptir (Hotchkiss vd., 2011; Qiao vd., 2010; You vd., 2007; Zhao vd., 2014).

İndiyum kalay oksit (ITO), sahip olduğu mekanik sertliği, düşük direnci, yüksek şeffaflığ 1 , kimyasal dayanımı gibi özelliklerinden dolayı OLED’ler de en çok tercih edilen anot malzemesidir $(\mathrm{H}$. Kim vd., 2002; Wang Hill, 2012; Zheng vd., 2018). Anot/boşluk taşıyıcı malzeme (HTM) ara yüzeyi, OLED gibi cihazların verimi, çalışma voltajı ve diğer özellikleri üzerinde önemli bir etkiye sahiptir (Zhong Jiang, 2006). Bu nedenlerden dolay1 metal/organik ara yüzeyi arasındaki temas ve enerji farkı problemini çözmek için ITO yüzeyi birçok farklı şekilde modifiye edilmeye çalışılmaktadır. Bu modifiye edici madde ve yöntemlerden bazıları, oksijen plazma (J. Kim vd., 1999), UV ozon (Li vd., 2005), Molibden trioksit $\left(\mathrm{MoO}_{3}\right)$ (You vd., 2007) $\operatorname{poly}(3,4-$ ethylenedioxythiophene)/poly(styrenesulfonate)(P EDOT/PSS) (Elschner vd., 2000) ve kendiliğinden organize olan molekülleridir (Q. Huang vd., 2006; Shang vd., 2018). Bu modifiye edici maddeler arasında PEDOT:PSS çok iyi optoelektronik özelliklere sahiptir. Bundan dolayı, PEDOT/PSS, kullanılan cihazlarda çok iyi verimlere ulaşılmaktadır. Fakat, PEDOT/PSS'in asidik özellik içermesinden dolayı zamanla ITO'yu aşındırması ve kolayca nemden etkilenmesi gibi dezavantajlarından ötürü cihaz veriminde ve kararlığında hızlı düşmelere neden olabilmektedir (Yalcin vd., 2018). Bu sebeplerden dolay1 PEDOT/PSS'e önemli bir alternatif olarak, ITO'nun modifiye edilmesinde, kendiliğinden organize olan moleküller kullanılmaktadır.

Teorik olarak, boşluklar bir dış elektrik alan altında ITO yüzeyinden $\mathrm{HTM}$ yüzeyine akarlar. $\mathrm{Bu}$ durumda, boşluklar hem ITO/HTM arasındaki enerji bariyeri hem de organik/anorganik arasındaki faz farkından kaynaklı temas direncini aşmaları gerekmektedir. ITO yüzeyi kendiliğinden organize olan moleküller ile kaplandığında boşluklar ITO yüzeyinden kendiliğinden organize olan moleküllere (organik faz) oradan da HTM yüzeyine (organik faz), düşük bir enerji gereksinimi ile, doğrudan geçerler (An vd., 2019).

Kendiliğinden organize olan moleküller çok küçük yapılar olup ITO yüzeyine kimyasal olarak bağlanarak yüzeyde çok ince ve kararlı bir yapı oluştururlar. $\mathrm{Bu}$ moleküller genellikle metal yüzeylerin fiziksel ve kimyasal özelliklerini kontrol etmek için kullanılır. Aynı zamanda, düşük maliyetli, kararlı ve esnek yüzeylere uygulanabilirlik (An vd., 2019) gibi özelliklerinden dolayı son y1llarda, ITO'nun modifiye edilmesinde sıkça kullanılmaya başlanılmıştır. Kendiliğinden organize olan moleküller ile hidrofilik özellik gösteren ITO ile hidrofobik özellik gösteren boşluk taşıyıcı malzeme arasındaki temas problemi ve enerji farkının azalması sağlanmaktadır (Klauk, 2010; Tokudome vd., 2011). Kendiliğinden organize olan moleküllerin sahip olduğu çeşitli fonksiyonel grup ve zincir uzunlukları sayesinde ITO'nun iş fonksiyonu istenilen şekilde ayarlanabilmektedir (Zheng vd., 2018). Bu şekilde ITO'nun iş fonksiyonu değiştirilerek, cihazın çalışma geriliminin düşürülmesi (Tokudome vd., 2011; Yalcin vd., 2017), yük geçişinin artırılması ve anot/organik malzeme arasındaki temas probleminin giderilmesi (Chong vd., 2007) gibi sorunların çözülmesi sağlanılmaktadır.

$\mathrm{Bu}$ çalışmada, iki farklı kendiliğinden organize olan molekül ile modifiye edilen ITO yüzeyinin 1slanabilirliği, pürüzlülüğü ve üretilen OLED cihazlarının elektriksel ve optiksel özelliklerinde meydana gelen değişim incelenmiştir. Elde edilen sonuçlar kendiliğinden organize olan moleküllerinin cihaz performansı üzerinde olumlu etkiye sahip olduğu gözlemlenmiştir. 


\section{Materyal ve metot}

\subsection{Kullanılan malzemeler}

Şekil 1 de molekül yapıları verilen 4-Metoksifenil Boronik Asit(1-Meo) ve 3,5-Dimeoksifenill Boronik Asit (2-Meo) yapıları kendiliğinden organize olan moleküller olarak kullanılmıştır. $\mathrm{Bu}$ moleküller dişında, N,N'-bis(3-metilfenil)(1,1'bifenil)-4,4'diamin (TPD) ve tris -(8hydroxyquinoline) aluminum $\left(\mathrm{Alq}_{3}\right)$ malzemeleri sırasıyla boşluk taşıyıcı yüzey (HTM) ve elektron emisyon yüzey (EML) olarak kullanılmıştır. Metal elektrotlar olarak ise ITO ve Alüminyum (Al) sirasiyla anot ve katot elektrotu olarak kullanılmıştır.<smiles>COc1ccc(B(O)O)cc1</smiles>

a

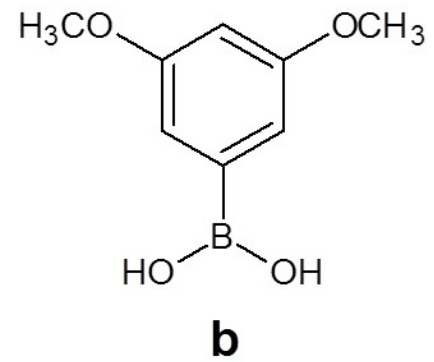

Şekil 1. 1-Meo (a) ve 2-Meo (b) moleküllerinin kimyasal yapıları.

\subsection{ITO'nun temizlenmesi}

ITO kaplı cam yüzeyler sirasıly saf su, aseton ve isopropil alkol içerisine daldırılarak 20 dakika boyunca ultrasonik banyoda yıkandi. Daha sonra ITO kaplı cam yüzeyler azot gazı ile kurutuldu. Kurulama işleminden sonra, ITO yüzeyinin aktifleştirilmesi için, yüzeyler vakum altında 8 dakika oksijen plazma (Electronic Diener Femto PCCE) ile temizleme işlemine maruz birakılarak temizleme işlemine son verildi.

\subsection{Cihaz üretimi}

Temizleme işleminden sonra ITO yüzeyler, dimetil sülfoksit (DMSO) içerisinde hazırlanan $10^{-3}$ molar'lık kendiliğinden organize olan moleküller (1-Meo, 2-Meo) çözeltisinde gece boyunca bekletilerek yüzeylerin bu moleküller ile kaplanması sağlandı. Kendiliğinden organize olan molekül çözeltisinden çıkarılan numuneler kendi çözeni olan DMSO ile iyice yıkanarak yüzeye iyi bağlanmamış olan moleküllerin yüzeyden uzaklaştırılması sağlandı. $\mathrm{Bu}$ işlemlerden sonra kendiliğinden organize olan moleküller ile kaplanmış ITO yüzeyleri, organik malzemeler
(TPD ve $\mathrm{Alq}_{3}$ ) ve metal elektrotun (Al) kaplamas1 için hazır hale gelmiş oldu.

$\mathrm{TPD}, \mathrm{Alq}_{3}$ ve $\mathrm{Al}$ malzemeleri $3 \times 10^{-6}$ torr'luk yüksek vakum altında termal evaporator (NANOVAK) ile kaplandi. Sirasiyla TPD ve $\mathrm{Alq}_{3}$ kalınlıkları $50 \mathrm{~nm}$ olacak şekilde kaplandı. Daha sonra katot elektrotu olan Al $100 \mathrm{~nm}$ olacak şekilde kaplanarak cihazın üretim aşaması tamamlandı. $\mathrm{Bu}$ çalışmada üretilen bir OLED cihazı ile mimari yapısı Şekil 2 de gösterilmiştir.

\subsection{Cihaz karakterizasyonu}

ITO yüzeylerinin, kendiliğinden organize olan moleküller ile kaplanmadan önceki ve kaplandıktan sonraki, yüzey topoğrafyaları ve yüzey pürüzlülükleri (Root Mean Square, RMS) Nanosurf Easyscan-2 Atomik Kuvvet Mikroskopu kullanılarak ölçülmüştür.

Temas açısı ölçümleri, KSV Attension Theta Lite optik gerilimölçer cihazı kullanılarak ölçümler her bir örnek numune üzerine yaklaşık $4 \mu \mathrm{L}$ saf su damlatılarak statik durumda ölçülmüştür.

Elektriksel ölçümler, akım-gerilim (I-V) ölçümleri, Keithly 2400 güç kaynağı ile lüminesans değerleri ise Admesy Brontes-colorimeter cihazı ile ölçülmüştür. a.

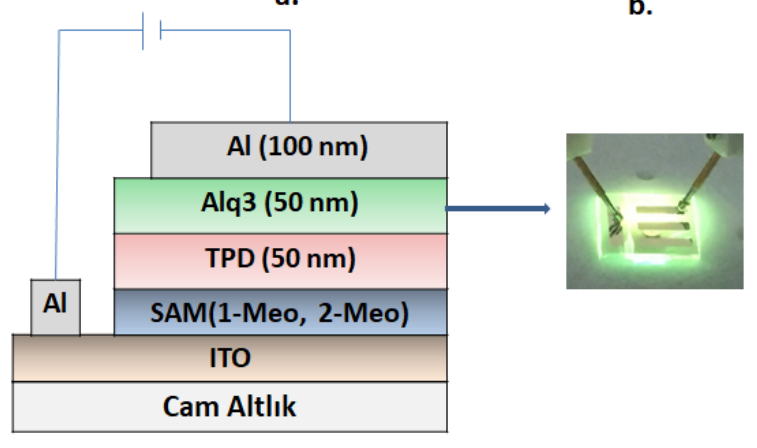

Şekil 2. Bu çalışmada üretilen bir OLED cihazının mimari yapıs1 (a) ve OLED Cihazı (b).

\section{Bulgular}

ITO yüzeyinin kendiliğinden organize olan moleküller ile kaplandığını tespit etmek için modifiye edilmiş yüzey ile modifiye edilmemiş yüzey topoğrafyaları Şekil 3 de gösterildiği gibi AFM ile ölçülmüştür. Ölçüm sonucu elde edilen yüzey pürüzlülük (RMS) değerleri sırası ile 1Meo/ITO, 2-Meo/ITO ve ITO için 3.9 nm, 3.6 nm ve $2.5 \mathrm{~nm}$ olarak elde edilmiştir. Yüzey pürüzlülüğündeki farklılıklar bize numunelerin 
kendiliğinden organize olan moleküller ile kaplandığını göstermektedir. $\mathrm{Bu}$ sonuçlar, kendiliğinden organize olan moleküllerin ITO'nun yüzey morfolojisi ve 1şı geçirgenliği üzerine negatif etki yaratmadığı aynı zamanda, moleküllerin ITO yüzeyi için düzgün HTM film oluşturduğunu göstermektedir (Can vd., 2014; Mi vd., 2020).

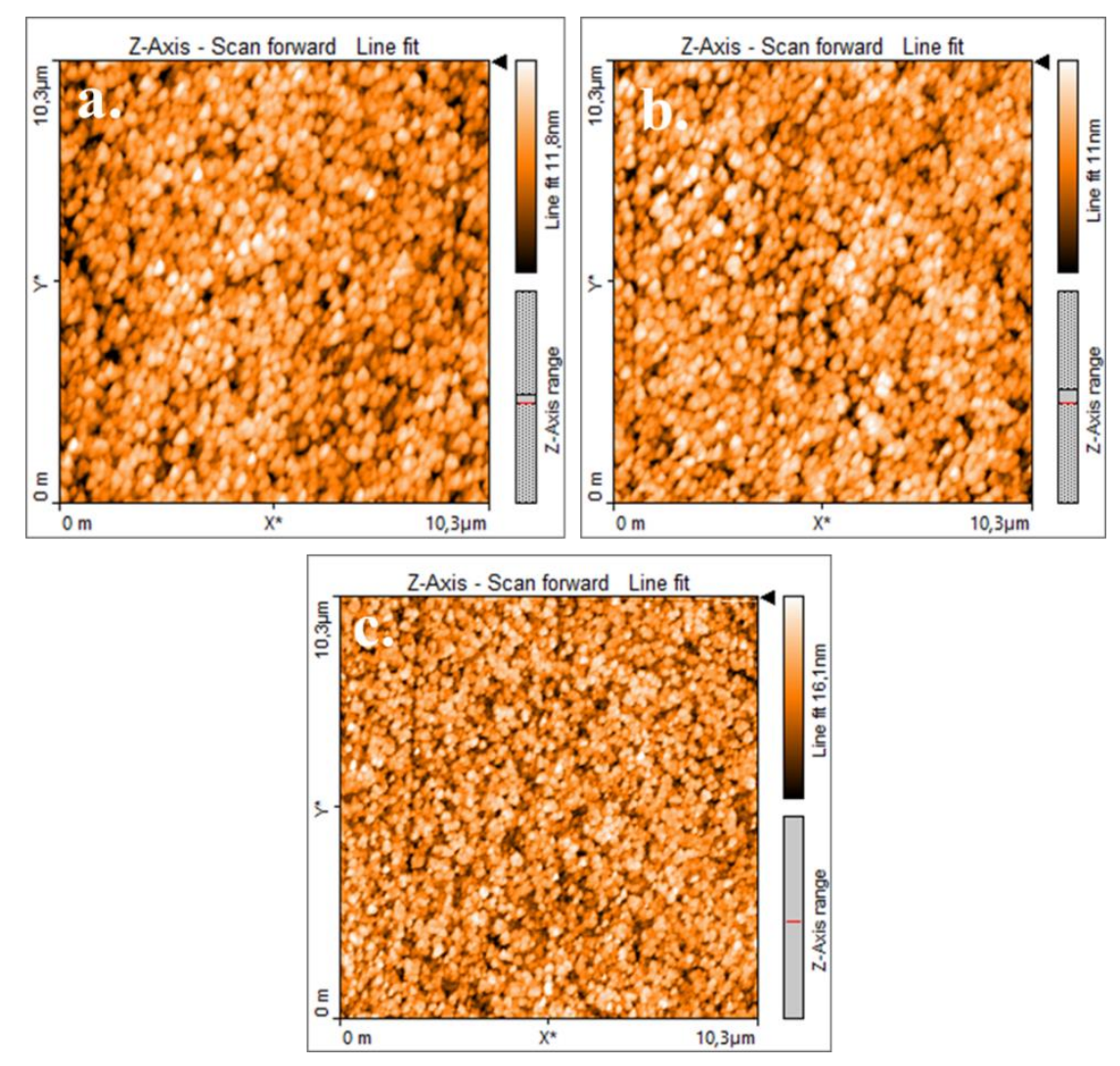

Şekil 3. 1-Meo (a), 2-Meo (b) ve ITO (c) nun yüzey topoğrafyası.

Bilindiği üzere ITO hidrofilik bir karaktere sahiptir. Bu da metal bir elektrot olan ITO ile organik bir malzeme olan TPD arasında bağlanma sorunlarına neden olmaktadır. Kendilğinde organize olan moleküllerin ITO yüzeyinin hidrofilik karakteri üzerine etkisininin incelenmesi için, ITO yüzeyi kendiliğinden organize olan moleküller ile kaplanmadan önceki ve kaplandıktan sonraki yüzey 1slanabilirliği Şekil 4 de gösterildiği gibi temas açısı yöntemi ile incelenmiştir. Şekil 4 de gösterilen 1-Meo/ITO, 2Meo/ITO ve ITO yüzeylerinin 1slanabilirlikleri sırasıyla $\sim 95^{\circ}, \sim 96^{\circ}$ ve $\sim 52^{\circ}$ olarak ölçülmüştür. $\mathrm{Bu}$ sonuçlar bize kendiliğinden organize olan moleküllerin ITO yüzeyi ile su arasında bir ara yüzey bariyeri oluşturduğunu göstermiştir. Böylelikle, ITO'nun hidrofilik özelliğinin perdelendiği tespit edilmiştir. Buna ek olarak, nemin cihaz kararlığını olumsuz etkilediği daha önceki çalışmalarda rapor edilmiştir (Mi vd., 2020). Bu çalışmada kullanılan kendiliğinden organize olan moleküllerin istenilen hidrofobik özellikler gösterdiği, böylelikle nemin cihaz içerisine geçişini zorlaştıracağıda söylenebilir.
Üretilen OLED cihazlarının akım yoğunluğugerilim, lüminesans-akım ve akım verimilüninesans grafikleri Şekil 5 de verilmiştir. Kendiliğinden organize olan moleküller ile modifiye edilen ITO'lar kullanılarak üretilen OLED cihazlarının çalışma geriliminin ITO ile üretilen cihazdan çok daha düşük olduğu, aynı şekilde kendiliğinden organize olan moleküller ile modifiye edilen cihazların daha düşük gerilimlerde daha yüksek akım yoğunluğuna sahip olduğu Şekil 5a dan görülebilmektedir. Böylelikle kendiliğinden organize olan moleküller ile modifiye edilen cihazların modifiye edilmemiş cihaza göre daha iyi bir yük iletkenliği sağladığını söyleyebiliriz. Şekil $5 b$ incelendiğinde ise, modifiye edilmiş cihazların daha iyi lüminesans değerlerine ulaştığı görülmektedir. $\mathrm{Bu}$ da bize etkin yük geçişine bağl1 olarak daha fazla elektron boşluk çifti taşınabildiği böylelikle daha yüksek lüminesans değerleri elde edildiğini göstermektedir. Cihazların akım verimi değerleri Şekil 5c de verilmiştir. Cihazlar en yüksek akım verimi değerlerine, sırasıyla ITO, 1Meo ve 2-Meo için $23.85 \mathrm{~cd} / \mathrm{cm}^{2}$ lüminesans, 77.22 $\mathrm{cd} / \mathrm{cm}^{2}$ lüminesans ve $127.19 \mathrm{~cd} / \mathrm{cm}^{2}$ lüminesans da 
ulaşmaktadır. Akım verimi ve lüminesans değerlerindeki bu iyileşme daha önce kendiliğinden organize tek katman molekülleri ile yapılan OLED çalışmalarınıda desteklemektedir (An vd., 2019; F. Huang vd., 2020; Kim vd., 2019).

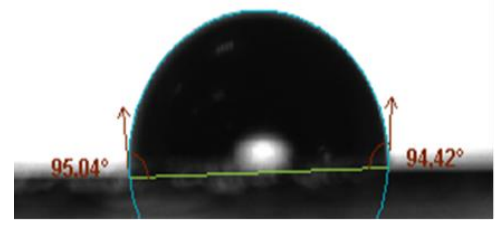

a.

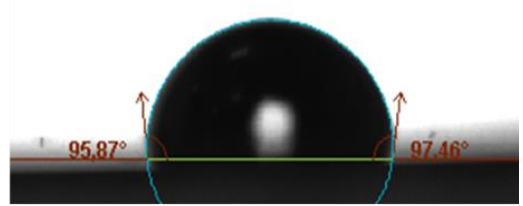

b.

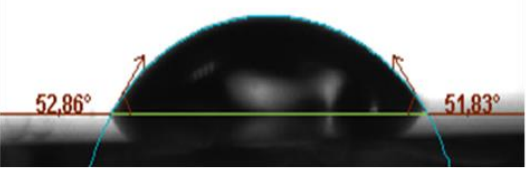

C.

Şekil 4. 1-Meo (a), 2-Meo (b) ve ITO (c) nun temas açıları.

a.

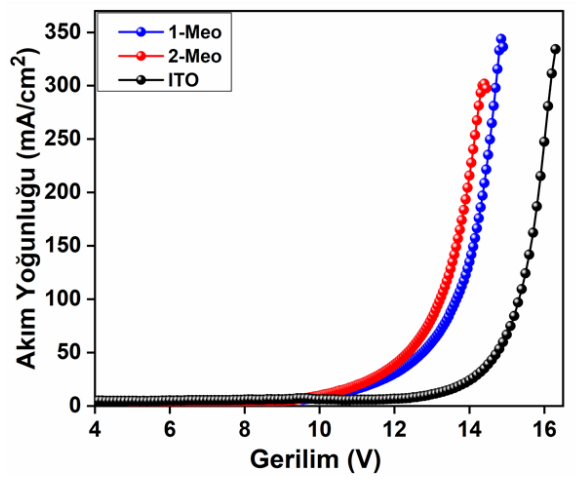

b.

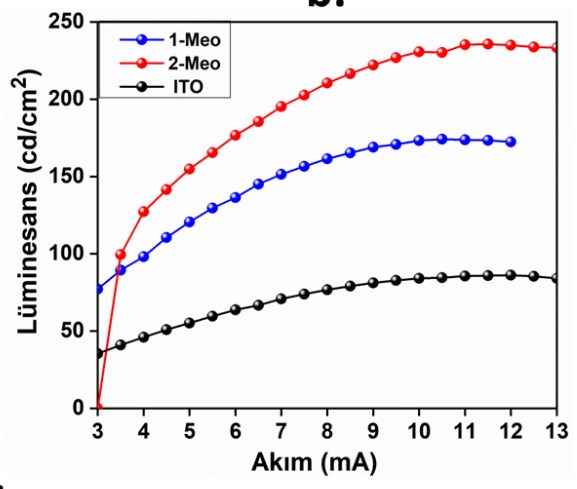

c.

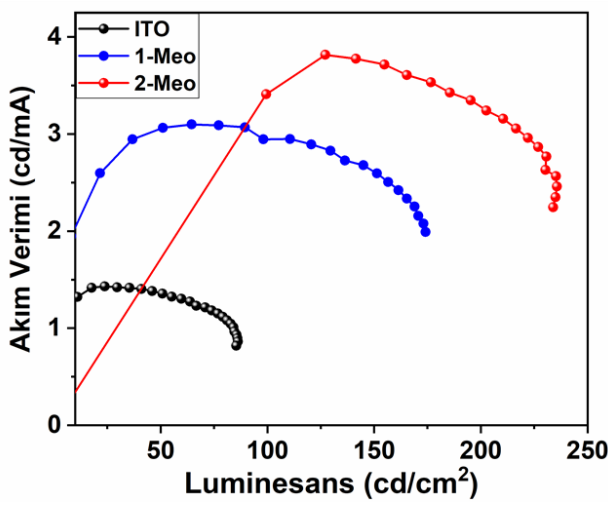

Şekil 5. 1-Meo, 2-Meo ve ITO'nun akım yoğunluğu-gerilim (a.) ve akım-lüminesans (b.) ve akım verimi-lüminesans grafikleri (c.).

\section{Sonuçlar}

Bu çalışmada iki tane kendiliğinden organize olan tek tabaka molekül (1-Meo ve 2-Meo) kullanılarak ITO yüzeyleri modifiye edilmiştir. Böylelikle metal elektrot olan ITO ile organik malzeme olan
HTM arasındaki temas problemi çözülmüştür. Aynı zamanda ITO dan organik yüzeye etkin bir yük geçişi sağlanmıştır. ITO yüzeyleri kendiliğinden organize olan moleküller ile modifiye edildikten sonra 1slanabilirlik karakteristlikleri temas açısı ile ölçülmüş ve 
modifiye edilen yüzeylerin hidrofobik karakteristliğinin arttığı görülmüştür. Benzer şekilde modifiye edilen yüzeylerin AFM ile yüzey topoğrafyalarına bakılmış ve yüzey pürüzlüğündeki değişmeler gözlemlenmiştir. Son olarak ise kendiliğinden organize olan moleküller ile modifiye edilen cihazların optoelektronik özellikleri incelenmiş ve optoelektronik özelliklerinde ciddi iyileşmelerin olduğu görülmüştür. 1-Meo ve 2-Meo molekülleri ile modifiye edilen cihazların lüminesans değerleri modifiye edilmemiş cihazınki ile karşılaştırıldığında lümineasan değerlerinde, sırasıyla, 2 kat ve 3 kattan fazla bir artış olduğu görülmüştür.

\section{Kaynaklar}

An, D., Liu, H., Wang, S. and Li, X. (2019). Modification of ITO anodes with self-assembled monolayers for enhancing hole injection in OLEDs. Applied Physics Letters, 114(15), 153301. https://doi.org/10.1063/1.5086800

Can, M., Havare, A. K., Aydin, H., Yagmurcukardes, N., Demic, S., Icli, S. and Okur, S. (2014). Electrical properties of SAM-modified ITO surface using aromatic small molecules with double bond carboxylic acid groups for OLED applications. Applied Surface Science, 314, 1082-1086.

https://doi.org/10.1016/j.apsusc.2014.05.181

Chong, L.-W., Lee, Y.L. and Wen, T.C. (2007). Surface modification of indium tin oxide anodes by selfassembly monolayers: Effects on interfacial morphology and charge injection in organic light-emitting diodes. Thin Solid Films, 515(5), 2833-2841.

https://doi.org/10.1016/j.tsf.2006.05.010

Elschner, A., Bruder, F., Heuer, H.-W., Jonas, F., Karbach, A., Kirchmeyer, S. and Wehrmann, R. (2000). PEDT/PSS for efficient hole-injection in hybrid organic light-emitting diodes. Synthetic Metals, 111, 139-143. https://doi.org/10.1016/S0379-6779(99)00328-8

Forrest, S. R. (2004). The path to ubiquitous and lowcost organic electronic appliances on plastic. Nature, 428(6986), 911.

Hotchkiss, P. J., Jones, S. C., Paniagua, S. A., Sharma, A., Kippelen, B., Armstrong, N. R. and Marder, S. R. (2011). The modification of indium tin oxide with phosphonic acids: mechanism of binding, tuning of surface properties, and potential for use in organic electronic applications. Accounts of Chemical Research, 45(3), 337-346. https://doi.org/10.1021/ar200119g
Huang, F., Liu, H., Li, X. and Wang, S. (2020). Highly efficient hole injection/transport layer-free OLEDs based on self-assembled monolayer modified ITO by solution-process. Nano Energy, 78 , 105399. https://doi.org/10.1016/j.nanoen.2020.105399

Huang, Q., Li, J., Evmenenko, G. A., Dutta, P. and Marks, T. J. (2006). Systematic Investigation of Nanoscale Adsorbate Effects at Organic LightEmitting Diode Interfaces. Interfacial StructureCharge Injection- Luminance Relationships. Chemistry of Materials, 18(9), 2431-2442. https://doi.org/10.1021/cm0604918

Kido, J., Kimura, M. and Nagai, K. (1995). Multilayer white light-emitting organic electroluminescent device. Science, 267(5202), 1332-1334. 10.1126/science.267.5202.1332

Kim, H., Horwitz, J., Kim, W., Mäkinen, A., Kafafi, Z. and Chrisey, D. (2002). Doped ZnO thin films as anode materials for organic light-emitting diodes. Thin Solid Films, 420, 539-543. https://doi.org/10.1016/S0040-6090(02)00836-2

Kim, H. R., Kim, T. W. and Park, S. G. (2019). Effective hole-injection characteristics of organic lightemitting diodes due to fluorinated self assembled monolayer embedded as a buffer layer. Polymer International, $\quad 68(8) . \quad 1478-1483$, https://doi.org/10.1002/pi.5853

Kim, J., Cacialli, F., Cola, A., Gigli, G. and Cingolani, R. (1999). Increase of charge carriers density and reduction of Hall mobilities in oxygen-plasma treated indium-tin-oxide anodes. Applied Physics Letters, 75(1). 19-21, https://doi.org/10.1063/1.124263

Klauk, H. (2010). Organic thin-film transistors. Chemical Society Reviews, 39(7), 2643-2666. https://doi.org/10.1039/B909902F

Li, C., Kwong, C., Djurišić, A., Lai, P., Chui, P., Chan, W. and Liu, S. (2005). Improved performance of OLEDs with ITO surface treatments. Thin Solid Films, $\quad 477(1-2), \quad 57-62$. https://doi.org/10.1016/j.tsf.2004.08.111

Mi, X., Rungo, B. A., Dong, X., Liu, H., Li, X. and Wang, S. (2020). Enhanced efficiency and stability of organic light-emitting diodes via binary self-assembled monolayers of aromatic and aliphatic compounds on indium tin oxide. Organic Electronics, 105752. https://doi.org/10.1016/j.orgel.2020.105752

Qiao, X., Tao, Y., Wang, Q., Ma, D., Yang, C., Wang, L. and Wang, F. (2010). Controlling charge balance and exciton recombination by bipolar host in single-layer organic light-emitting diodes. Journal of Applied Physics, 108(3), 034508. https://doi.org/10.1063/1.3457672 
Shang, Z., Liu, D., Wang, T., Yu, X., Li, B., Li, W. and Zhou, X. (2018). Enhanced Hole-Injection Property in an OLED with a Self-assembled Monolayer of Hole-Transporting TPD on Thin $\mathrm{Au}$ as the Anode. Transactions of Tianjin University, 1-7. https://doi.org/10.1007/s12209018-0161-7

Tokudome, Y., Fukushima, T., Goto, A. and Kaji, H. (2011). Enhanced hole injection in organic lightemitting diodes by optimized synthesis of selfassembled monolayer. Organic Electronics, 12(10)

1600-1605. https://doi.org/10.1016/j.orgel.2011.06.022

Wang, M. and Hill, I. G. (2012). Fluorinated alkyl phosphonic acid SAMs replace PEDOT: PSS in polymer semiconductor devices. Organic Electronics, $\quad$ 13(3), 498-505. https://doi.org/10.1016/j.orgel.2011.12.008

Yalcin, E., Can, M., Rodriguez-Seco, C., Aktas, E., Pudi, R., Cambarau, W. and Palomares, E. (2018). Semiconductor self-assembled monolayers as selective contacts for efficient PiN perovskite solar cells. Energy \& Environmental Science. 10.1039/C8EE01831F

Yalcin, E., Kara, D. A., Karakaya, C., Yigit, M. Z., Havare, A. K., Can, M. and Aboulouard, A. (2017). Functionalized organic semiconductor molecules to enhance charge carrier injection in electroluminescent cell. Optical Materials, 69,
283-290.

https://doi.org/10.1016/j.optmat.2017.04.038

You, H., Dai, Y., Zhang, Z. and Ma, D. (2007). Improved performances of organic light-emitting diodes with metal oxide as anode buffer, Journal of Applied Physics, 101 (2), 06105, https://doi.org/10.1063/1.2430511

Zhao, Y., Duan, L., Zhang, D., Dong, G., Qiao, J., Wang, L. and Qiu, Y. (2014). Systematic Investigation of Surface Modification by Organosiloxane Self-Assembled on Indium-Tin Oxide for Improved Hole Injection in Organic Light-Emitting Diodes. ACS Applied Materials \& Interfaces, 6(6), 4570-4577. https://doi.org/10.1021/am500399e

Zheng, H., Zhang, F., Zhou, N., Sun, M., Li, X., Xiao, Y. and Wang, S. (2018). Self-assembled monolayer-modified ITO for efficient organic light-emitting diodes: The impact of different self-assemble monolayers on interfacial and electroluminescent properties. Organic Electronics, 56, 89-95. https://doi.org/10.1016/j.orgel.2018.01.038

Zhong, Z. and Jiang, Y. (2006). Surface modification and characterization of indium-tin oxide for organic light-emitting devices. Journal of Colloid and Interface Science, 302(2), 613-619. https://doi.org/10.1016/j.jcis.2006.07.009 